\title{
THE USE OF THE AUTOMATED DIGITAL ZENITH CAMERA SYSTEM IN ISTANBUL FOR THE DETERMINATION OF ASTROGEODETIC VERTICAL DEFLECTION
}

\author{
Müge Albayrak ${ }^{1,2}$ - ORCID: 0000-0001-6705-4044 \\ Kerem Halıcıoğlü - ORCID: 0000-0002-2500-8581
}

Mustafa Tevfik Özlüdemir ${ }^{1}$ - ORCID: 0000-0002-1413-9244

Burak Başoğlu ${ }^{1}$ - ORCID: 0000-0002-3702-1257

Rasim Deniz ${ }^{1}$ - ORCID: 0000-0003-1519-1025

Allison RB Tyler ${ }^{4}$ - ORCID: 0000-0002-0350-7267

Mohammed Mohseni Aref ${ }^{1,5}$ - ORCID: 0000-0003-3735-178X

${ }^{1}$ Istanbul Technical University, School of Civil Engineering, Department of Geomatics Engineering, Istanbul, Turkey. E-mail: albayrakmug@itu.edu.tr; tozlu@itu.edu.tr; basoglub@itu.edu.tr; denizr@itu.edu.tr

${ }^{2}$ The Ohio State University, School of Earth Sciences, Columbus, OH, USA. E-mail: albayrak.6@osu.edu

${ }^{3}$ Freie Universität Berlin, Institute of Mathematics, Berlin, Germany. E-mail: kerem.halicioglu@fu-berlin.de

${ }^{4}$ University of Michigan, School of Information, Ann Arbor, MI, USA. E-mail: arbtyler@umich.edu

${ }^{5}$ Postdam University, Institute of Geosciences, Postdam, Germany. E-mail: mohseniaref@uni-postdam.de

Received in 06 ${ }^{\text {th }}$ September 2019

Accepted in $22^{\text {nd }}$ September 2019

\begin{abstract}
:
The Digital Zenith Camera Systems (DZCSs) are dedicated astrogeodetic instruments used to obtain highly accurate astrogeodetic vertical deflection (VD) data. The first Turkish DZCS, the Astrogeodetic Camera System (ACSYS), was developed in Istanbul, Turkey in 2015. The ACSYS was capable of determining astrogeodetic VDs with an accuracy of $\sim 0.3$ arcseconds. However, it had some limitations in observation duration: because of the semi-automated mechanical design, levelling the system towards zenith was a time-consuming process. Since 2016, the ACSYS has been modernized through system upgrades and new technological components. In this paper, we describe the instrument design of the new DZCS-ACSYS2-observation procedures, evaluation of the test data and calculations of these data. The preliminary ACSYS2 astrogeodetic test observations were conducted at Istanbul Technical University (ITU) test station. The standard deviation results of the repeated observations reveal a VD measurement precision of $\sim 0.3$ arcseconds for both the North-South and East-West components. To investigate the accuracy of the system, a lightweight total station
\end{abstract}

How to cite this article: ALBAYRAK, M.; HALICIOĞLU, K.; ÖZLÜDEMIR, M. T.; BAŞOĞLU, B.; DENIZ, R.; TYLER, A. R. B.; AREF, M. M. The use of the automated digital zenith camera system in Istanbul for the determination of astrogeodetic vertical deflection. Bulletin of Geodetic Sciences. 25(4): e2019025, 2019. 
based-geodetic system-QDaedalus-was also used at the ITU test station. The comparison of the VDs data between ACSYS2 and QDaedalus system shows that the ACSYS2 can produce reliable VDs data.

Keywords: Vertical deflections, Astrogeodetic Measurement, Geodetic instrumentation, Digital zenith camera system, QDaedalus, Accuracy and precision.

\section{Introduction}

The Helmert definition of vertical deflection (VD) is the angular difference between the direction of the gravity vector or plumbline at a point of the Earth's surface, and the ellipsoidal surface's normal through the same point for a particular ellipsoid (Jekeli 1999; Featherstone and Rüeger 2000). The Helmert VD is the most common VD (Jekeli 1999). Therefore, it is also often referred to as an astrogeodetic VD (Hirt 2010). The other two kinds of VDs-Molodensky and Pizetti-differ slightly from the Helmert VDs by the curvature of the plumbline (Jekeli 1999; Torge and Müller 2012).

Astrogeodetic VDs provide valuable information about the structure of Earth's gravity field. For this reason, astrogeodetic observations are essential gravity field observables. Currently, research teams in several countries have developed modern instruments, such as Digital Zenith Camera System (DZCS) or the totalstation based QDaedalus system, both of which are operated at field stations at night, that are used to observe astronomical coordinates (astronomical latitude $\Phi$ and longitude $\Lambda$ ). GNSS receivers located at the same benchmark provide geocentric geodetic coordinates (geodetic latitude $\varphi$ and longitude $\lambda$ ). From these, the North-South $(\xi=\Phi-\varphi)$ and East-West $(\eta=(\Lambda-\lambda) \cos \varphi)$ components of VDs can be calculated (e.g., Heiskanen and Moritz 1967; Voigt 2013; Schack et al. 2018). Second- and higher-order terms, which are neglected here, are provided in Pick et al. (1973) and Jekeli (1999).

DZCSs have created a dynamic research environment, particularly for astronomical research, and have lent new motivation to astronomy and geodesy. The motivation gained during this period of rapid technological change and development has contributed to more efficient data collection and analysis efforts: e.g., astrogeodetic applications, such as geometric-astronomical levelling (Hirt and Bürki 2006; Hirt et al. 2011), astrogeodetic geoid determination (Smith et al. 2013; Wang et al. 2017), validation of height unifications and gravity field models (Hirt and Flury 2008; Schack et al. 2018), local geodetic network applications (Volařík et al. 2013; Halıcıoğlu et al. 2016), and monitoring of anomalous refraction research (Hirt 2006; Hirt 2012), among others. The main purpose of a DZCS in this study is for local geoid determinations, which are particularly beneficial for measurements in coastal and mountainous areas (Hirt and Bürki 2003; Hirt et al. 2010a).

The first DZCS in Turkey, the Astro-geodetic Camera System (ACSYS), was developed in 2015. The ACSYS was capable of determining astronomical coordinates $(\Phi, \Lambda)$ with an accuracy of $\sim 0.3^{\prime \prime}$. However, it had significant limitations, especially in observation duration. Since the beginning of 2016, the ACSYS has been modernised through a series of system upgrades, including new technological components, hardware and software, and is known as the ACSYS2.

In this paper, we describe the modernisation process, the instrument design of the ACSYS2, the observation procedures, evaluation of the test data and calculations of these data. Five nights of preliminary astrogeodetic test observations were conducted with the ACSYS2 at the Istanbul Technical University (ITU) station. The results of the repeated and comparative VD observations indicate a VDs measurement precision of approximately $0.3^{\prime \prime}$. To investigate the accuracy, we used the lightweight total station-based geodetic measurement system, 'QDaedalus', developed at ETH Zurich (Bürki et al. 2010; Guillaume et al. 2012; Charalampous et al. 2015; Tóth and Völgyesi 2018). 


\section{Historical background of the Digital Zenith Camera System}

Classical geodetic astronomy (astrogeodesy) is concerned with the determination of astronomical observables, such as astronomical latitude and longitude, and azimuth from ground-based optical direction measurements to fixed stars, processes which also require precise time determination (Müller 1969; Schödlbauer 2000; Torge and Müller 2012). Several types of observational instruments have been used for this purpose. Until the 1970s, geodetic astronomical observations were done with optical observation instruments, such as Astrolabes, T4, and DKM3A theodolites (Figure 1). The use of these instruments required not only well-trained and skilled observers but also long observation durations (Hirt and Bürki 2006; Hirt et al. 2010a).

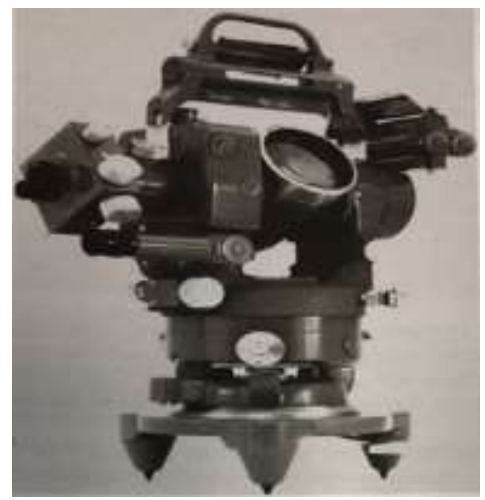

(a) Kern DKM3-A

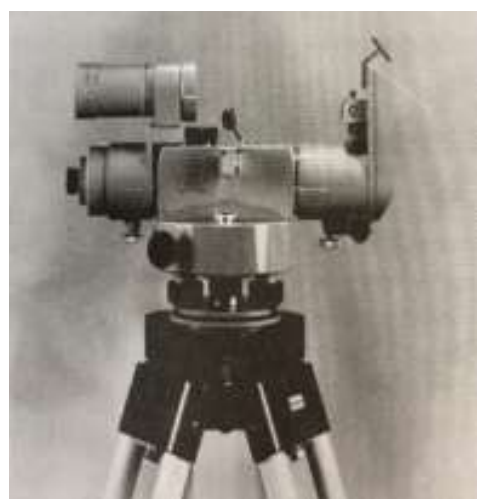

(b) Zeiss Ni2 level with prism astrolabe

Figure 1: Optical observation instruments (Torge and Müller 2012, p. 164).

After the 1970s, the major improvements of astrogeodetic observation techniques were achieved through the development of photographic zenith cameras at the University of Hannover (Gessler 1975; Wissel 1982) and ETH Zurich (Bürki 1989). The ETH Zurich photographic (analogue) zenith camera (Figure 2) consisted of a telescope, a microprocessor-control camera, two electronic levels of Talyvel $\amalg$, and an electronic control unit and a level display (Bürki and Marti 1991). Moreover, Italian (Birardi 1976) and Austrian (Chesi 1984) institutions developed similar instruments for astrogeodetic observations. Photographic zenith cameras minimized operator-related observational errors. Because of the fully automated registration of exposure epochs and level readings, there were high levels of precision and simplified observation procedures with these systems as compared to the old systems. These systems were used in many European and American countries (e.g., Switzerland, Austria, Germany, Denmark, Greece, Canada, Brazil, Venezuela). However, the acquisition of star coordinates from the images was performed manually or semi-automatically using a comparator, and the process at a single station usually took 3-5 hours. As well, due to the development of efficient satellite positioning and gravity field determination methods, the importance of astrogeodetic methods decreased (Hirt and Bürki 2006; Hirt et al. 2010a).

Astrogeodesy studies were revolutionised in the 2000s by the invention of the digital imaging sensor technology (charged-couple device-CCD). The most common existing photographic zenith cameras-Transportable Zenith Cameras (TZK2 and TZK3) - which were using photographic films were re-designed and equipped with CCD cameras (Figure A1 in the Appendix). The TZK2 at the University of Hannover is called the Transportable Zenith Camera 2 - Digital system (TZK2-D), whereas the CCD-implemented system at ETH Zurich is called the Digital Astronomical Deflection Measuring system (DIADEM). CCD integrated, and fully automated digital systems are generally called DZCSs. They were extensively used for local and regional gravity field determinations (Hirt and Bürki 2006; Hirt et al. 2010a). 


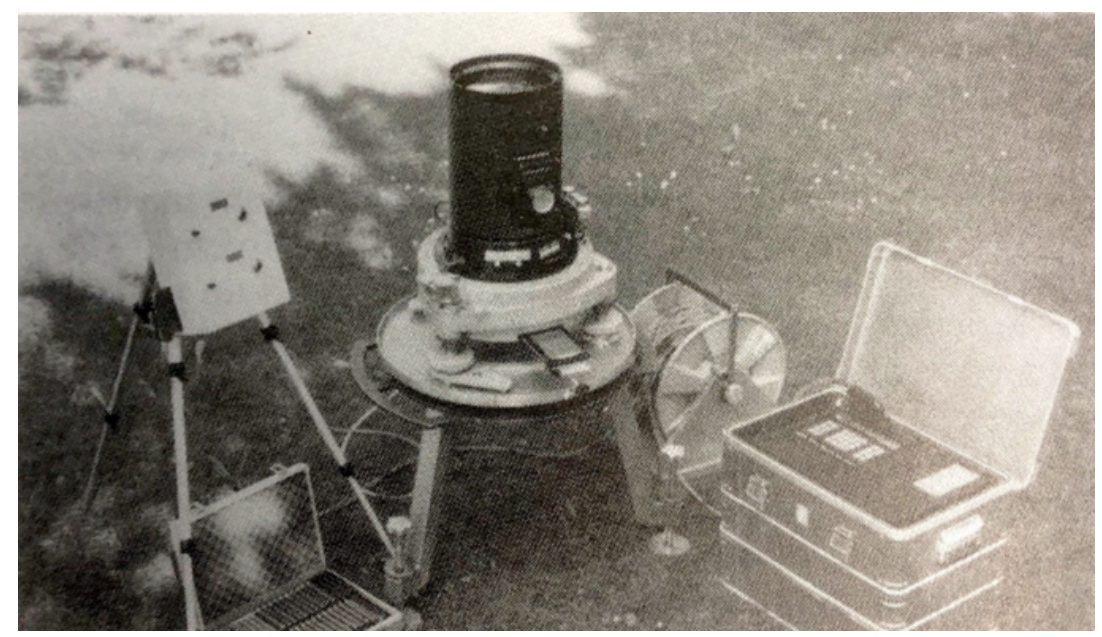

Figure 2: ETH Zurich photographic zenith camera. The electronic control unit is on the right-hand side of the photo, and the level display is mounted on a small tripod, left-hand side of the photo (Bürki and Marti 1991).

As effective and fully automated systems, the development of the DZCSs in Germany and Switzerland (e.g., Hirt and Bürki 2003; Bürki et al. 2004; Hirt 2004; Müller et al. 2005; Hirt and Seeber 2008; Hirt et al. 2010a) have inspired many other researchers in geodesy, particularly astrogeodesy. Scientists in several countries have developed their own DZCSs: Poland (Kudrys 2007), Latvia (Abele et al. 2012; Zarinš et al. 2016; Zarins et al. 2018), Turkey (Halıcıoğlu et al. 2012; Halıcıoğlu et al. 2016), China (Wang et al. 2014; Tian et al. 2014) and Hungary (Hirt et al. 2014). Each of these systems has unique design features, including hardware components and automation software. Moreover, technological changes have affected all versions of the DZCS. The DIADEM was redesigned by the Institute of Geodesy and Photogrammetry of ETH Zurich and renamed the Compact Digital Astronomical Camera (CODIAC) (Guillaume 2015; Wang et al. 2017). Its main purpose in replacing the DIADEM is to reduce instrument size and cost and to meet industry standards to facilitate use by non-astrogeodetic experts. The CODIAC (an accuracy level of up to $0.05^{\prime \prime}$ ) has been successfully utilised in many important projects, such as the Geoid Slope Validation Surveys in lowa (Wang et al. 2017) and Colorado (Westrum et al. 2019) in the USA.

As an alternative to the DZCS, a light-weight TS-based geodetic measurement system, QDaedalus, was designed and built at the Institute of Geodesy and Photogrammetry at ETH Zurich. The QDaedalus system consists of a TS, CCD camera, mountable front lens, low-cost u-blox LEA-6T single-frequency GNSS receiver, and a computer for instrument control, imaging and processing (Bürki et al. 2010; Guillaume et al. 2012; Charalampous et al. 2015; Tóth and Völgyesi 2018). The QDaedalus system's user manual not only explains system installation and how to conduct observations, but it also provides the formulae for VD calculation (Guillaume et al. 2015). The QDaedalus hardware components and measurements process are also explained in Tóth and Völgyesi (2017) and Hauk et. al (2017), and the first investigations of the precision (internal accuracy) and accuracy of the QDaedalus system are given by Hauk et al. (2017). The QDaedalus system has also been used for daytime terrestrial applications, such as engineering surveying and deformation, vibration, and frequency analysis (Bürki et al. 2010; Charalampous et al. 2015; Guillaume et al. 2016), the short-term characteristics of terrestrial refraction (Hirt et al. 2010b), and photographic documentation (Bürki et al. 2010). 


\section{Instrumental design and observation procedure of the astrogeodetic camera system 2}

The first Turkish DZCS, the Astrogeodetic Camera System (ACSYS), was developed in Turkey in 2015 (Figure 3). The system components include a telescope, a CCD camera, two tiltmeters with the resolution of 0.01 milliradian [mrad], a focuser, a single frequency GPS receiver (the CNS Clock II), which is used for determining time, a GNSS receiver for highly accurate geodetic coordinates and a substructure (Halıcıoğlu et al. 2012).

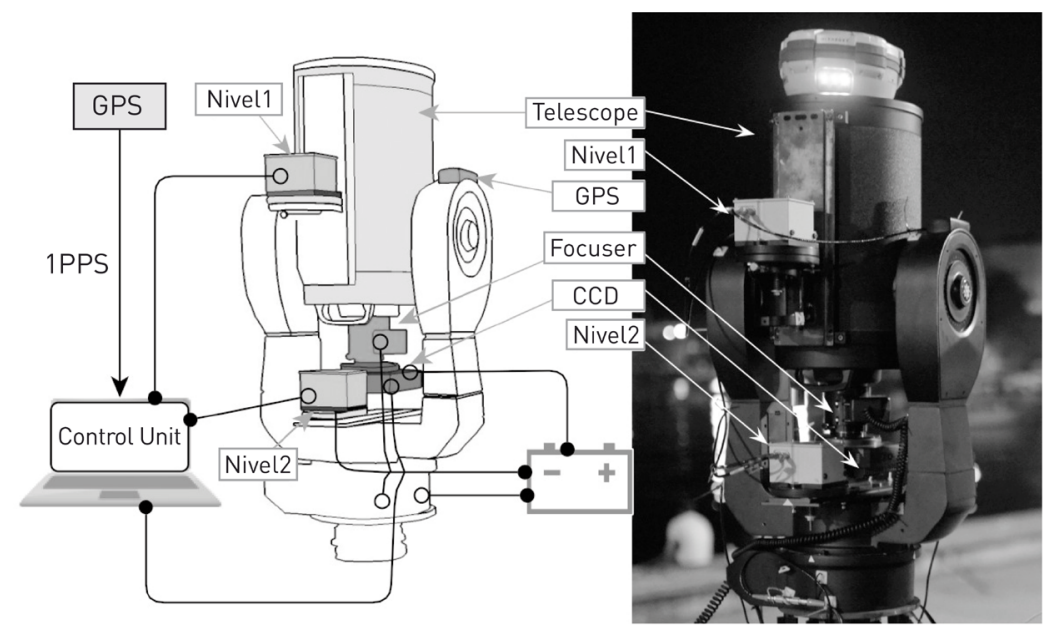

Figure 3: ACSYS: The First Turkish Digital Zenith Camera System (Halıcıoğlu et al. 2016).

The precision of the ACSYS was determined to be $0.3^{\prime \prime}$ when determining both the astronomical latitude and longitude (Halıcıoğlu et al. 2016) through repeated observations at the test station of Boğaziçi University, the Kandilli (KNDL) station, on the Asia side of Istanbul. Halıcıoğlu et al. (2016) determined the accuracy of this ACSYS $\left(\sim 0.3^{\prime \prime}\right)$ by comparing the GNSS/levelling geoid height differences with the derived geoid height differences using the astronomical levelling technique. This was done while establishing the test network with four benchmarks (Figure 4); however, there were some limitations of the ACSYS based on the observation durations. Because of the semi-automated mechanical design, use of the standard industrial tribrach for the levelling was a time-consuming process (Albayrak et al. 2017 and 2018a).

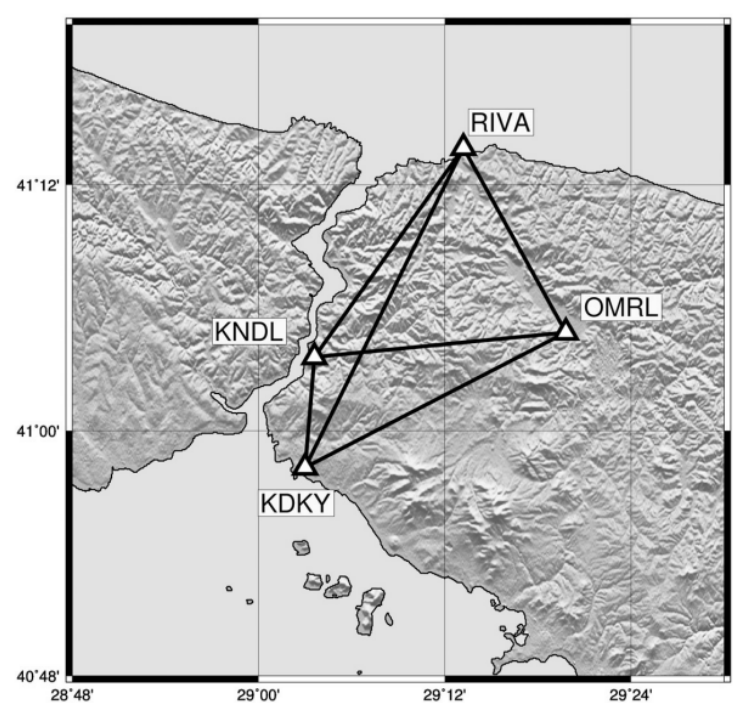

Figure 4: The first version of the ACSYS' test network in Istanbul (Halıcıoğlu et al. 2016). 
The utilisation of a tribrach as the supporting substructure not only prolonged the levelling process but had many other disadvantages. The total weight of the instrument (approximately $30 \mathrm{~kg}$ ) and design of the system produce a tilting effect that needed to be adjusted through a system-specific levelling procedure: iterative levelling (Halıcıoğlu et al. 2017a, 2017b). Also, the total weight of the system made transport logistically difficult and required a wheeled substructure design. Therefore, work began in 2016 to automate the observation and data processing procedure, with the support of the Scientific and Technological Research Council of Turkey (TUBITAK). In the scope of this project, a supporting substructure was designed based on the lessons learned from previous measurement campaigns that would facilitate the utilisation of the ACSYS during observations (Figure 5). The trolley of the new design was influenced by the success of the CODIAC design (Guillaume 2015), one of the most recently designed DZCS.

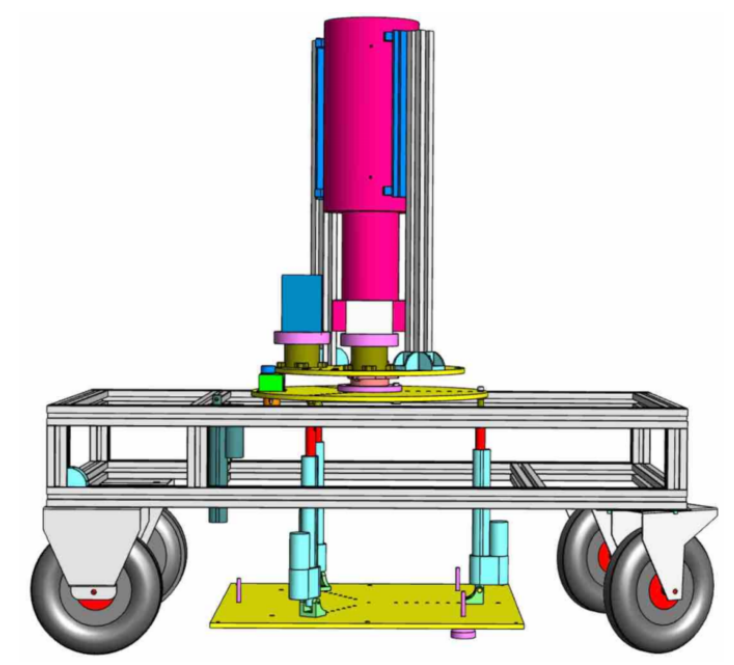

Figure 5: The new design of the Astrogeodetic Camera System 2.

The modernization and upgrade process of the new design of the ACSYS-ACSYS2-includes precise digital sensors: installation of a high-resolution tiltmeter (HRTM) with a resolution of 1 nano-radians $\left(10^{-6} \mathrm{mrad}\right)$, implementation of a temperature compensating focuser $\left(\mathrm{TCF}\right.$, resolution of $0.1^{\circ} \mathrm{C}$ ) and a fully automated substructure system (Figure 6). The system components are controlled by specially designed and unified astrogeodetic data processing software (ADAPS).

The technical components of ACSYS and ACSYS2 are provided in Table 1. With the realization of ACSYS2 design, the levelling process, which previously took a long time and required significant user experience, has been automated. The installation and levelling process takes an average of $\mathbf{2 0}$ min. thanks to this supporting substructure design, as compared to an average of $40 \mathrm{~min}$. with the ACSYS. 

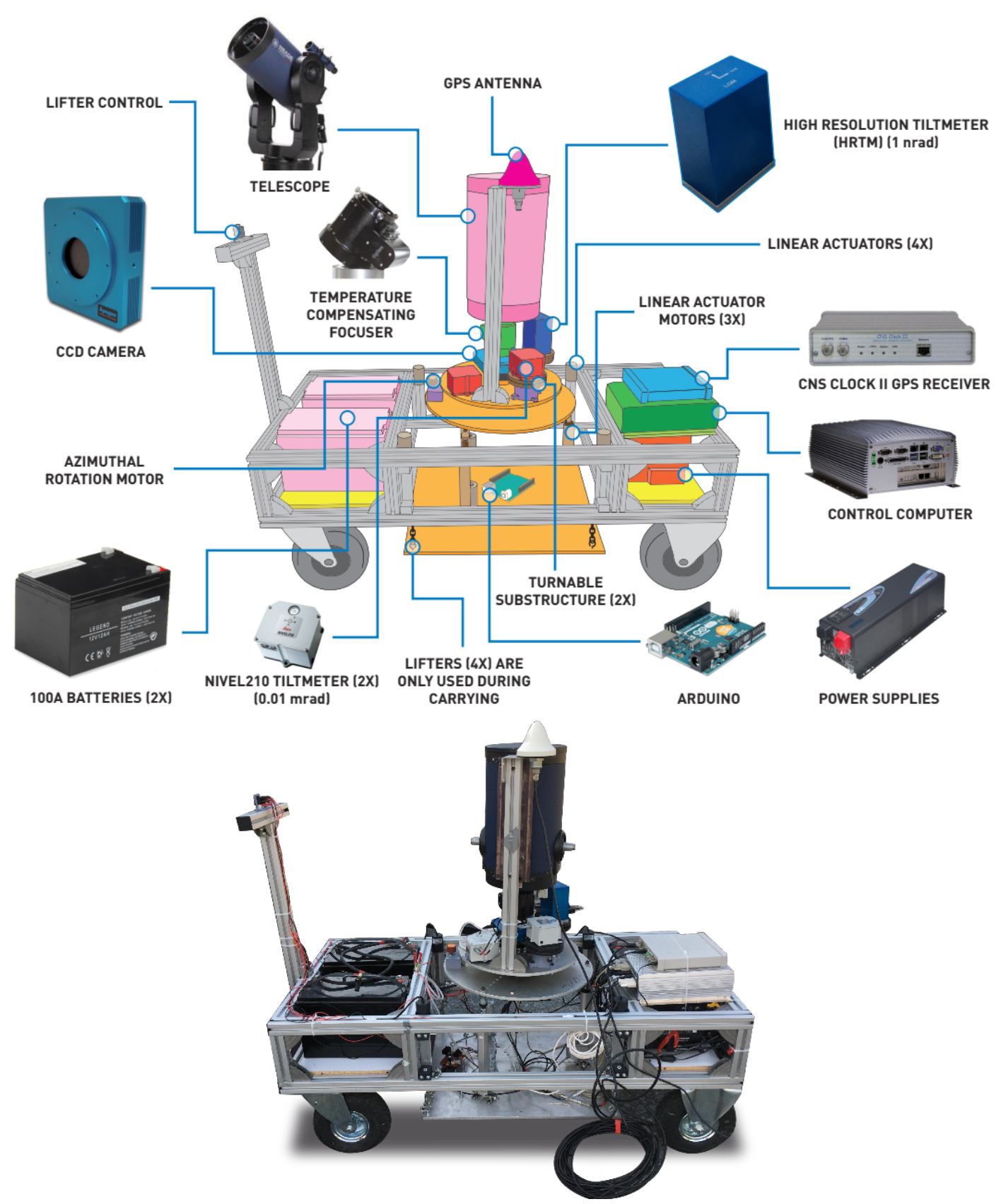

Figure 6: The realisation of the Astrogeodetic Camera System 2.

Table 1: The technical components of ACSYS and ACSYS2.

\begin{tabular}{c|c|c}
\hline Component & ACSYS & ACSYS2 \\
\hline CCD camera & Apogee 32 & Apogee 32 \\
\hline Telescope & Meade LX200 GPS (8",f/10) & Meade LX200 GPS (8",f/10) \\
\hline GPS receiver for timing & CNS Clock II & CNS Clock II \\
\hline Tiltmeter & Leica Nivel 210 [0.01 mrad] & Leica Nivel 210 [0.01 mrad] \\
\hline & & HRTM* (1 nano-rad) \\
\hline Focuser & Meade Focuser & TCF** \\
\hline Substructure & Industrial Tripod & Specially designed \\
\hline
\end{tabular}

HRTM*: High-resolution tiltmeter, TCF**: Temperature compensating focuser 


\subsection{The industrial design of the ACSYS2}

\section{Levelling}

In order to reduce the levelling time, the levelling procedure of the system was automated through linear actuator motors in the ACSYS2. First, a rectangular plaque was installed on the carriage. Three linear actuator motors, their linear actuator connecting apparatus, and their ball joint created a link between the rectangular plaque and the bottom round plaque (cf. Figure 6). Three apparatus supplied with three linear actuators were observed to hinder the stability of the system. Therefore, another three apparatus that would increase the rigidity of the system was provided. By re-positioning the upper round plaque to a horizontal position, the system can be made level with the assistance of three linear actuator motors.

The levelling procedure of the system is a two-stage process. The first one aims to level the base plane (substructure) of the system using linear actuator motors. The second stage is to level the system using an iterative process until the threshold value, provided by the observer, is reached. The second step is done by the linear actuator motors as follows: two of the three linear actuator motors are moved up and down until the circular level bubble sets of tiltmeters are in the centre. The motionless third linear actuator motor is set to an upright position relative to the other two. By only moving this linear actuator motor up and down, the $\mathrm{X}$-tilt and $\mathrm{Y}$-tilt values of the tiltmeters and the upper round plaque are set in a horizontal position. The threshold value for our observations was set to be less than $0.02 \mathrm{mrad}$. Levelling is performed for each azimuthal direction that the measurements are performed. The whole process is controlled and analysed by modified ADAPS developed for this study (Uluğ et al. 2017; Albayrak et al. 2018a). Tilt values for each azimuthal direction conform to radial symmetrical behaviour and are calculated using an iterative approach in the least square adjustment, using the iterative levelling process (Halıcıoğlu 2015; Halicioglu et al. 2016). The tilt values are constantly saved and correlated to image epochs, and the end values are obtained by correcting the levelling.

To increase the accuracy of the levelling, we used the high-resolution electronic inclination sensor, HRTM, which has a nano-radian resolution. While the HRTM was used for the first time in Turkey in 2016, the Hannover DZCS research group first integrated it into the Hannover DZCS TZK2-D in 2002 (Hirt 2004; Kahlmann et al. 2004; Hirt and Kahlmann 2004). Hirt and Kahlmann (2004) preferred the HRTM because it not only had the highest accuracy, but it also had extremely low noise characteristics. In their work, they investigated the HRTM's sensor behaviour under changing temperatures. We also followed their practices when we tested the HRTM's characteristics and sensor stability under different environmental conditions by comparing it to the Nivel210 tiltmeter (Uluğ et al. 2017; Uluğ 2017). We conducted test measurements at Boğaziçi University's Kandilli Observatory and Earthquake Research Institute (KOERI) for 30 days. In that study, the air chamber and vibration table were also used to investigate the correlation between temperature and tilt values (Figure 7). We found that the HRTM sensor achieves very high accuracy under various challenging conditions and that it can be used for the ACSYS2 (Uluğ et al. 2017; Uluğ 2017). In addition, the HRTM has been used in many scientific and engineering research projects across Europe, such as the development of CODIAC, where four HRTMs were integrated into that DZCS (Guillaume 2015).

\section{Azimuth calibration}

To eliminate instrumental axis misalignment errors, images are taken in different azimuths. For this reason, the azimuth calibration in the ACSYS2 is performed for four azimuthal directions separated by $90^{\circ}$ using an Arduino-system.

\section{Focuser}

The clarity of the star images acquired with ACSYS2 carries critical importance for identifying the stars and the resolution process. The clarity of the star images varies depending on temperature. Therefore, the analogue focuser of the present system was upgraded to one that is sensitive to temperature changes, called the temperature compensating focuser. 

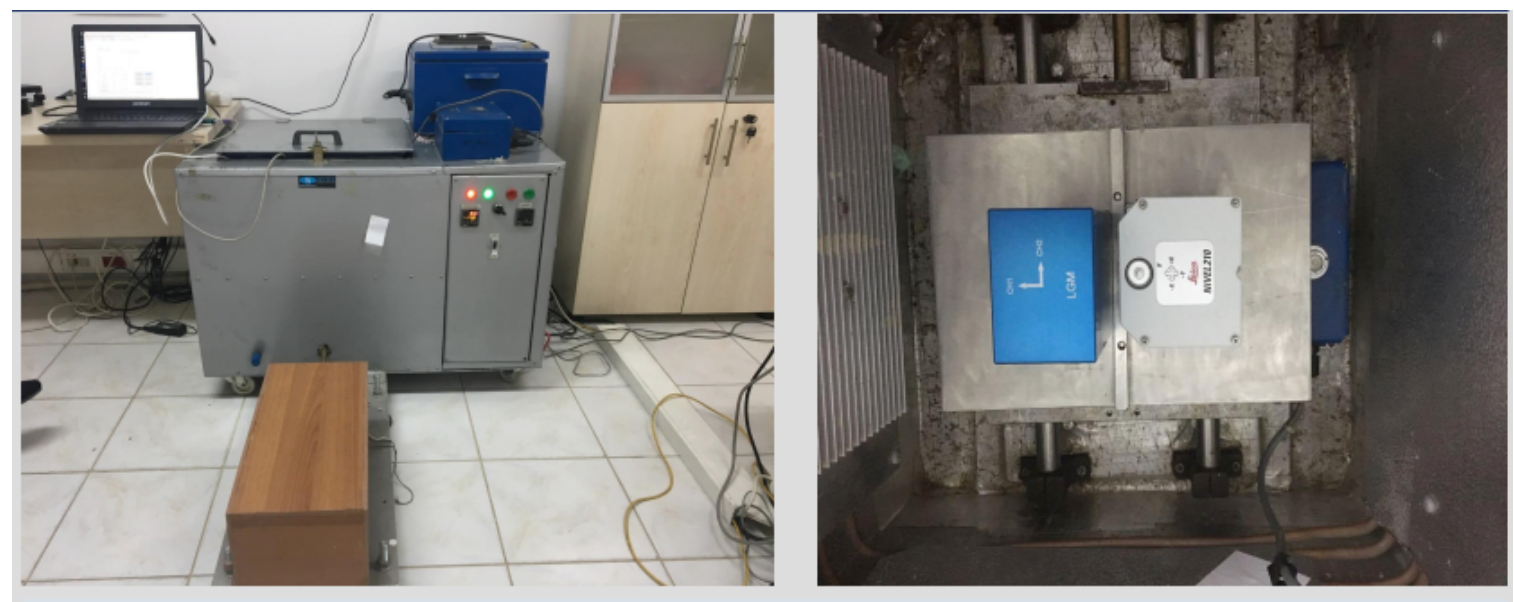

Figure 7: Air chamber and vibration table (Uluğ et al. 2017).

\section{Observation principle and data processing strategy}

\subsection{Observation principle}

There is a specific procedure that must be followed before observations which include levelling and hardware tests. For levelling, $X$-tilt and $Y$-tilt values of the tiltmeters are recorded in $0^{\circ}, 90^{\circ}, 180^{\circ}$ and $270^{\circ}$ azimuthal directions values. It is expected that tilt values would have a radial symmetrical behaviour around the zenith. It is necessary to determine the best fitting circle in least-squares sense. The whole iterative process is controlled and analysed by software until the predefined threshold value is reached.

The radius of the best fitting circle is used to realign the system towards the zenith, the iterative levelling process defined in Halıcıoğlu et al. (2016). The radius correction is done by the linear actuator motors attached to the substructure. The levelling software and the graphics display of tilt values can also be examined during the levelling procedure (Figure 8). Therefore, it is possible to analyse any potential gross error during the observation. Furthermore, the software controls the observation procedure and analyses if there is a need to repeat the levelling procedure. After the system is levelled and a successful instrumental alignment towards the zenith, the observation process begins.
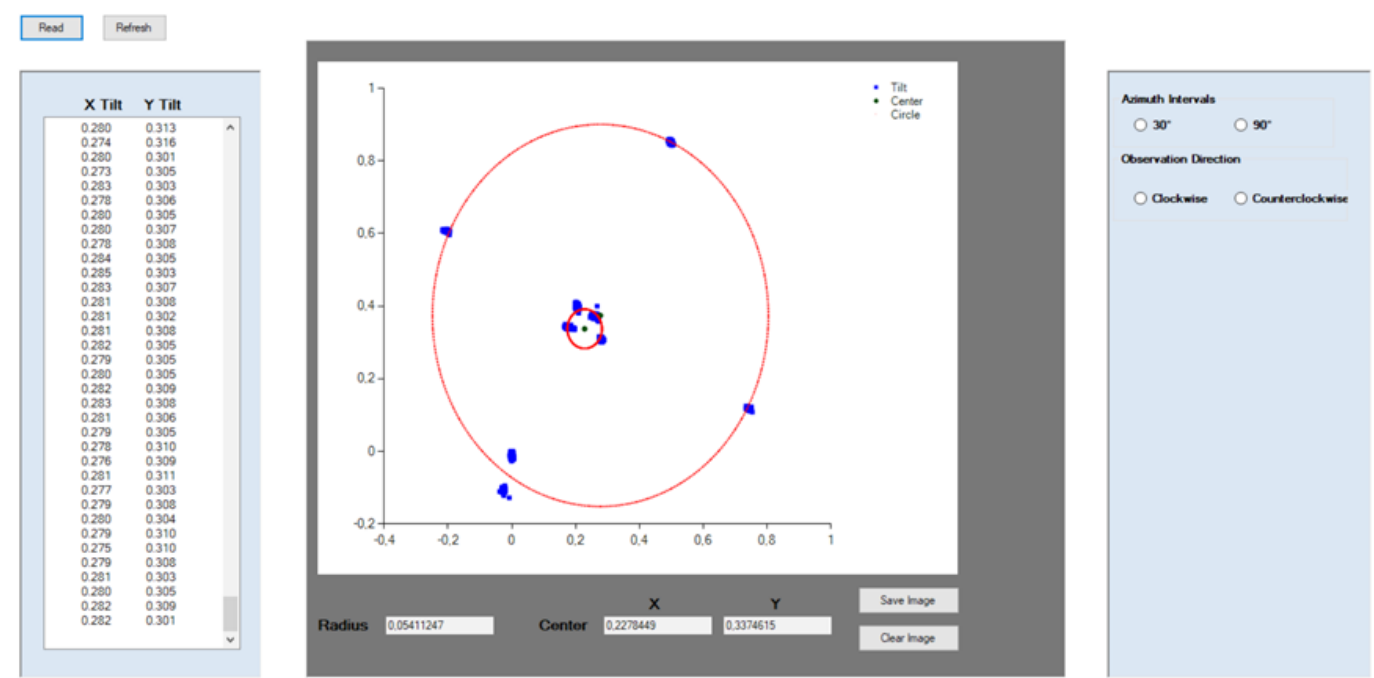

Figure 8: The circle fit codes prepared for levelling the system (Başoğlu 2019).

Bulletin of Geodetic Sciences, 25(4): e2019025, 2019 
During the observations, the exposure time for the CCD camera is chosen as 0.3 seconds. 4 series of 10 images each are obtained at each azimuth, leading to a total of 160 time- and tilt-tagged images captured during a standard observation night. The images are tagged using the epoch-dependent tilt values and used as corrections to the final coordinates.

\subsection{Data processing}

The stars in the acquired images are identified with the help of precision star catalogues such as the USNO CCD astrograph Catalogue 4 (UCAC4). The first step in data evaluation follows the astrometric reduction process, and therefore the stars in the captured images are identified. The possible stars in the images are identified using star centroiding algorithms, such as the point-spread function (PSF) method (Lauer 1999; Lafreniere et al. 2007). Detected time-tagged stars are associated with the stars in the star catalogues. A star exactly located at zenith (Figure 9), astronomical coordinates $(\Phi, \Lambda)$ and equatorial coordinates $(\alpha, \delta)$ of a BM can be linked with the Greenwich Apparent Sidereal Time (GAST [ $\theta]$ ) using these equations (Torge and Müller 2012, p. 168):

$$
\Phi=\delta, \quad \Lambda=\alpha-\theta
$$

For this action, approximate coordinates of the image center must be known in the equatorial system. The star is identified by the system's focus distance, local sidereal time and CCD camera geometry, which are then matched with the star coordinates in the UCAC4 catalogue (Zacharias et al. 2013). Determining potential stars and comparing them to catalogue information is comparatively done using pinpoint astrometric engine (Pinpoint Astrometric Engine 2019), WCSTools (WCSTools 2019) software and the software package for ACSYS2, modified from the first version of the ADAPS (see Halıcıoğlu et al. 2016).

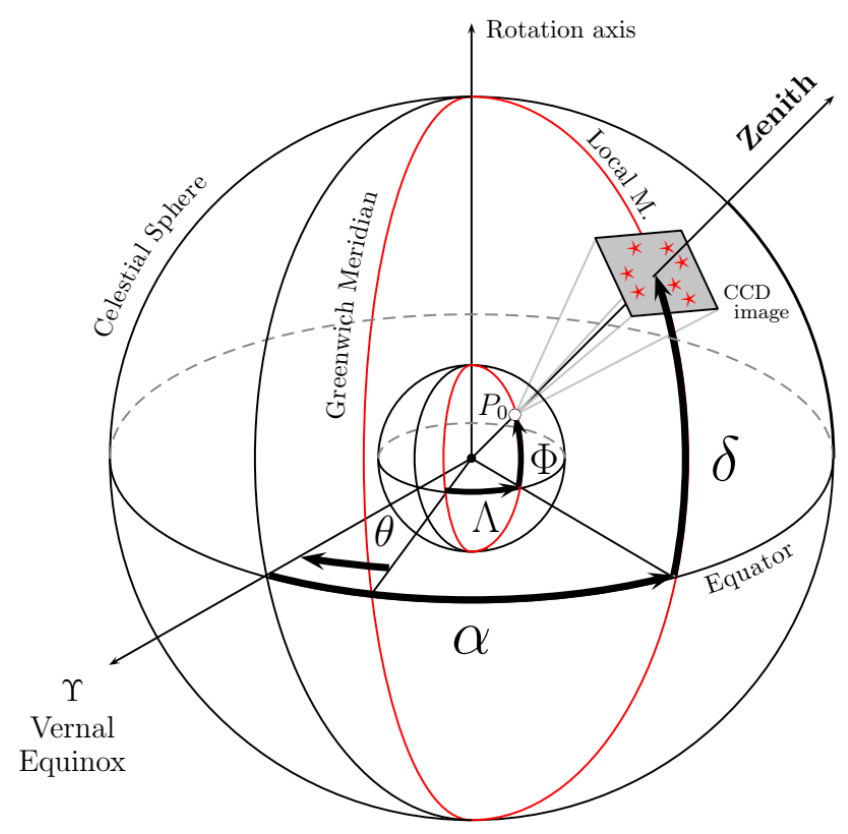

Figure 9: Zenithal star field and direction of the local plumb line (modified from Hirt et al. 2010a).

After the astrometric reduction process (Smart 1977), detected image stars and identified catalogue stars are compared through the standard deviations (SDs) of the matched stars. In practice, the SD is selected to be less than 0.3 arcseconds, and the stars that exceed this threshold value are not taken into account for the determination of zenithal coordinates. This process is calculated using software based on the USNO NOVAS C libraries developed 
by the USNO (Kaplan et al. 2011). To calculate apparent topocentric coordinates, algorithms given by Kaplan et al. (1989) and the Greenwich Apparent Sidereal Time (GAST) is calculated using the algorithms given by Kaplan (2005). Apparent Topocentric Coordinates are then used to calculate equatorial coordinates of the zenithal point through astrometric reduction procedure using an iterative approach. Astronomical coordinates, calculated as a result of the star images, and the geodetic coordinates are used to obtain the VD components. The simplified steps of ACSYS are shown in Figure 10. The calculation of the VD components is explained by Halıcıoğlu et al. (2012 and 2016) and the lengthy process will not be replicated in this paper.

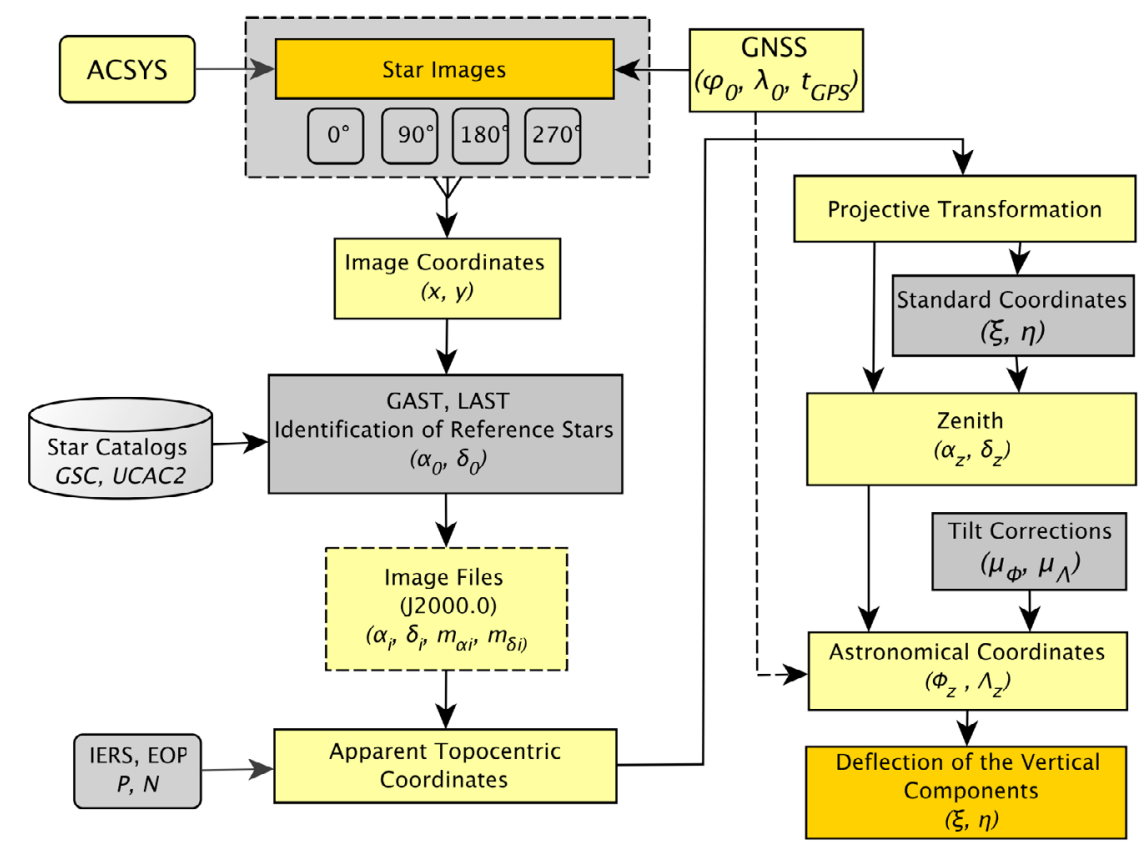

Figure 10: Data processing steps of ACSYS (Halıcıoğlu et al. 2016).

\section{Results}

\subsection{Investigation of the precision of the ACSYS2}

Astrogeodetic test observations were conducted with the ACSYS2 at ITU's Ayazaga Campus, European side of Istanbul, Turkey (Figure 11). The geodetic coordinates of the ITU test station were used to calculate the astrogeodetic VDs data, and were obtained via rapid static GNSS measurement, with reference to the ITRF96 reference frame and 2005.0 epoch ( $\varphi=41^{\circ} 06^{\prime} 12.80635^{\prime \prime}, \lambda=29^{\circ} 01^{\prime} 10.82185^{\prime \prime}, \sigma_{\varphi, \lambda} \leq \pm 2 \mathrm{~cm}$ ).

Five nights of preliminary astrogeodetic test observations were conducted with the ACSYS2 at the ITU test station to determine the precision of the instrument. The observed VDs were obtained through 2-4 observation sessions, resulting in 80-160 time- and tilt-tagged images (10 images are obtained at each of the four azimuths) at 0.3 seconds exposure time each night. The mean of each night's VDs data and the difference between the mean values and the average values can be seen in Table 2. Overall, the differences between the mean and average values are satisfactory for both the North-South and East-West components. The average SD across the 5 nights of measurements (for nightly mean values) is 0.30 " for the North-South $(\xi)$ and 0.27 " for the East-West $(\eta)$ components.

We intended to conduct 4 observation sessions per night. As seen in Table 2, in February, four sessions of VDs observations were conducted. Then, we extended the exposure times up to 60 seconds to investigate the best 
solutions for acquiring accurate astronomical coordinates (Halıcıoğlu et al. 2018 and 2019). However, in March, technical malfunctions and inclement weather precipitated the premature end to observations.

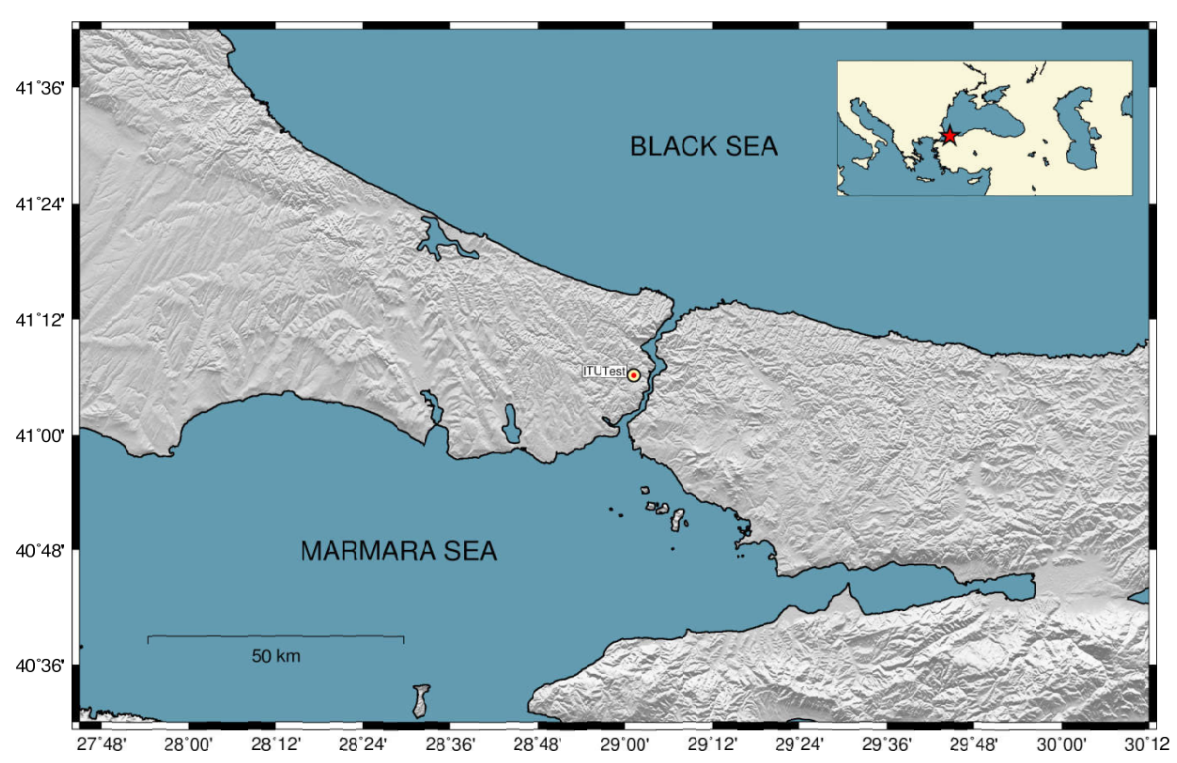

Figure 11: Location of the Istanbul Technical University (ITU) test station.

Table 2: The obtained nightly mean VDs data using ACSYS2 at the ITU test station.

\begin{tabular}{c|c|c|c|c|c}
\hline Date & Sessions & $\xi["]$ & $\eta\left[{ }^{\prime \prime}\right]$ & $v_{\xi}\left[{ }^{\prime \prime}\right]$ & $v_{\eta}\left[{ }^{\prime \prime}\right]$ \\
\hline $09-02-18$ & 4 & 1.70 & 2.97 & 0.02 & 0.16 \\
\hline $13-02-18$ & 4 & 1.96 & 3.02 & -0.24 & 0.11 \\
\hline $11-03-18$ & 3 & 1.54 & 3.16 & 0.18 & -0.03 \\
\hline $29-03-18$ & 2 & 2.06 & 3.58 & -0.34 & -0.45 \\
\hline $30-03-18$ & 3 & 1.33 & 2.90 & 0.39 & 0.23 \\
\hline & Average & 1.72 & 3.13 & & \\
\hline
\end{tabular}

\subsection{Investigation of the accuracy of the ACSYS2}

The total station-based QDaedalus system was used to investigate the accuracy of the ACSYS at the ITU test station. The QDaedalus system developer created various combinations of the CCD camera that can be clipped onto the different types of total station (Guillaume et al. 2016). In this study, we used the Leica TCRM1101 total station, which was tested at the Technical University of Munich (TUM) control station repeatedly before, during, and after the observations were made at the ITU test station (Albayrak et al. 2018c). Hauk et al. (2017) investigated the optimum length of astrogeodetic observations and determined that $15 \mathrm{~min}$. observation sessions were adequate to provide good VD results $\left(0.15^{\prime \prime}-0.20^{\prime \prime}\right)$. For this reason, the astrogeodetic measurements were executed at $\sim 15$ min. session duration, and 3 or 4 sessions were carried out at the TUM control site and ITU test station as weather permitted. We found the precision and accuracy of the system at the TUM control site to be $~ 0.20$ " for both the North-South and East-West components (Albayrak et al. 2018c and 2019).

The QDaedalus (TCRM1101 TS) astrogeodetic observations were conducted on six different nights to collect VDs data at the ITU test station (Albayrak et al. 2019), which can be seen in Table 3. The system was installed seven 
times; due to cloud cover on August 3, 2018, which interrupted observations, the system was installed twice. We were unable to do a second series of observations from either installation. Overall, the differences between the nightly mean and average values (from the 7 installations) are satisfactory for both the North-South and East-West components. The SDs for the measurements (calculated from each installation's mean solutions) is 0.20 " and 0.14 " for the North-South $(\xi)$ and East-West $(\eta)$ components, respectively.

Table 3: The obtained nightly mean VDs data using the Leica TCRM1101 TS integrated QDaedalus system at the ITU test station.

\begin{tabular}{c|c|c|c|c|c}
\hline Date & Sessions & $\xi\left[{ }^{\prime \prime}\right]$ & $\eta\left[{ }^{\prime}\right]$ & $v_{\xi}\left[{ }^{\prime \prime}\right]$ & $v_{\eta}\left[{ }^{\prime}\right]$ \\
\hline $08-02-18$ & 2 & 1.45 & 3.56 & 0.09 & -0.23 \\
\hline $09-03-18$ & 4 & 1.92 & 3.27 & -0.38 & 0.06 \\
\hline $20-03-18$ & 4 & 1.57 & 3.12 & -0.03 & 0.21 \\
\hline $09-06-18$ & 3 & 1.66 & 3.31 & -0.12 & 0.02 \\
\hline $30-07-18$ & 2 & 1.39 & 3.38 & 0.15 & -0.05 \\
\hline $03-08-18(1)$ & 1 & 1.32 & 3.43 & 0.22 & -0.10 \\
\hline $03-08-18(2)$ & 1 & 1.47 & 3.23 & 0.07 & 0.10 \\
\hline & Average & 1.54 & 3.33 & & \\
\hline
\end{tabular}

These data from the QDaedalus system were then compared against the ACSYS2 VDs data at the ITU test station. The VD results of both systems are plotted in Figure 12, and both systems were deployed on the same night (March 20, 2018) in order to have directly comparable results (the system set-ups can be seen in Figure A2 in the Appendix). Due to weather conditions, we could not conduct the observation with ACSYS2 on March 20, 2018.

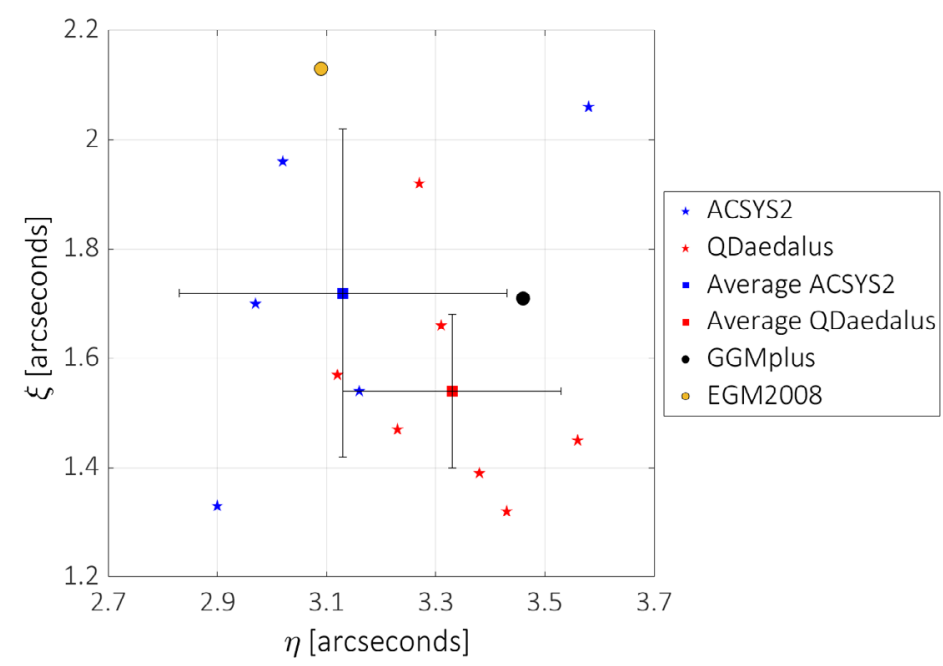

Figure 12: Measured VDs from the night-time observations at the ITU test station using the ACSYS2 and Leica TCRM1101 total station integrated QDaedalus system.

\subsection{VD Comparisons at the Istanbul Technical University}

Astrogeodetic VDs from the Global Gravity Model plus (GGMplus) gravity field maps (Hirt et al. 2013) and EGM2008 (Pavlis et al. 2012, 2013) were used for comparisons with the observed astrogeodetic VDs from ACSYS2 and 
QDaedalus at the ITU test station. The GGMplus VDs are based on satellite (GRACE, GOCE) and EGM2008 gravimetric gravity field observations, entirely independent from the astrogeodetic techniques (Albayrak et al. 2019).

The QDaedalus astrogeodetic VDs accuracy is $0.20 "$ for both the North-South and East-West components. Because of the high accuracy of the QDaedalus VDs, they were preferred as the reference VD values for comparison with the other astrogeodetic VDs data at the ITU test station (Table 4, Figure 13).

Table 4: Comparison of astrogeodetic VDs (measured with the QDaedalus system and ACSYS2, and modelled with GGMplus and EGM2008).

\begin{tabular}{c|c|c|c|c}
\hline Method & $\xi["]$ & $\eta["]$ & $v_{\xi}\left[{ }^{\prime \prime}\right]$ & $v_{\eta}\left[{ }^{\prime \prime}\right]$ \\
\hline QDaedalus (reference) & 1.54 & 3.33 & & \\
\hline ACSYS2 & 1.72 & 3.13 & -0.18 & 0.20 \\
\hline GGMplus & 1.71 & 3.46 & -0.17 & -0.13 \\
\hline EGM2008 & 2.13 & 3.09 & -0.59 & 0.24 \\
\hline
\end{tabular}

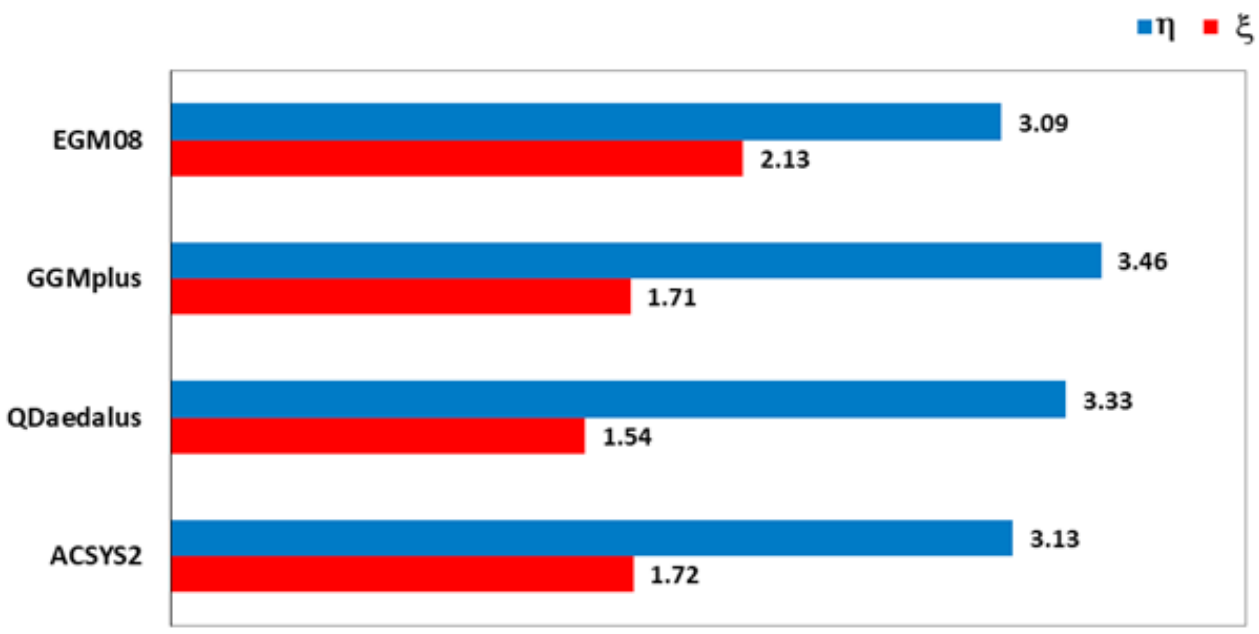

[all units are arcseconds]

Figure 13: Comparison of astrogeodetic VDs.

\section{Discussions}

\subsection{Modernization process of the ACSYS2}

The DZCS development studies in Turkey began in 2008 (Halıcıoğlu et al. 2008), and the development process and the first results from the ACSYS were published in 2016 (Halıcıoğlu et al. 2016). Since 2016, the modernization of the ACSYS has been ongoing by the Istanbul DZCS research group. In this paper, we have reported on the modernization process and the first obtained results of this 3 years process.

Aspects of the modernization process have been published in various venues: (a) the testing and calibration of the ACSYS2 components (Halıcıoğlu et al. 2017b; Uluğ et al. 2017; Uluğ 2017), (b) star catalogs and centroiding algorithm (Başoğlu et al. 2017; Başoğlu 2019), (c) the modernization and upgrading process of the ACSYS2 (Albayrak et al. 2017, 2018a and 2018b; Başoğlu 2019), and (d) the first astrogeodetic test observation results (Albayrak et 
al. 2018a and 2018b). The research team has obtained star images at various exposure times in order to test the best solutions for acquiring highly accurate astronomical coordinates. In this paper, we obtained the astrogeodetic coordinates with 0.3 second exposure times. These coordinates' accuracies not only depend on the precision of sensors, but they also depend on the image processing method. The new method to increase the number of stars in the images-extending the exposure time up to 60 seconds-was investigated by Halıcıoğlu et al. $(2018,2019)$. With this method of image processing, it is possible to improve the accuracy of the astronomical coordinates using fitting functions of the star trails.

\subsection{The precision and accuracy of the ACSYS2}

The precision of the first version of the ACSYS was determined to be $0.3^{\prime \prime}$ through repeated observations at the test station of Boğaziçi University, on the Asian side of Istanbul. However, in this study, we could not use that test station at Boğaziçi University, due to the inaccessibility of the station (obstructed by the construction of a new building). We established a new test station for ACSYS2 at ITU, on the European side of Istanbul. The ACSYS2's precision was determined to also be $\sim 0.3$ " through repeated observations at that ITU test station.

The conventional method of determining the accuracy of the astrogeodetic instrument is to conduct comparative and repeated measurements with other astrogeodetic instruments: for example (a) the accuracy of the Hannover DZCS TZK2-D was determined by using existing Hamburg photographic zenith tube (PZT) station (Hirt et al. 2005) and parallel measurements with DIADEM in Switzerland (Müller et al. 2005; Hirt et al. 2010a); and (b) the Leica TCA2003 TS integrated QDaedalus system's accuracy was determined using existing TZK2-D VDs data (Hauk et al. 2017). However, the accuracy of the first version of the ACSYS was determined by comparing the GNSS/levelling geoid height differences with the derived geoid height difference using the astronomical levelling technique (Halıcıoğlu et al. 2016). This method, by Halıcıoğlu et al. (2016), is an alternative method which can be used in countries devoid of accurate astrogeodetic VD datasets.

The accuracy of the ACSYS2 was investigated by a conventional method, using the Leica TCRM1101 total station integrated QDaedalus system. This QDaedalus system was tested at the TUM control site and the obtained accuracy was 0.20 " for both the North-South and East-West components. The accuracy was also compared with Leica TCA2003 and TDA5005 TS integrated QDaedalus system at the TUM control site (Albayrak et al. 2018b). These accuracies of the QDaedalus system provide a more reliable accuracy for the ACSYS2. The average VD differences between ACSYS2 and QDaedalus at the ITU test station are $-0.18^{\prime \prime}$ and $0.20^{\prime \prime}$ for the North-South and East-West components, respectively (cf. Table 4). These satisfactory results of the ACSYS2 show that the ACSYS2 produces accurate VDs data. However, we plan to carry out comprehensive VD measurements of the ACSYS2 at the same ITU test station before its full use in fieldwork. This additional testing will develop more reliable measures of precision and accuracy of the system.

The comparison between the observed VDs from QDaedalus measurements and the modelled VDs from GGMplus and EGM2008 at the ITU test station show that the GGMplus and EGM2008 VDs data have very good agreement with the QDaedalus system (cf. Table 4). Albayrak et al. (2019) found that the GGMs have good agreement with observed VDs data in the internal zone (i.e., far from the coastline) of Istanbul.

\subsection{The importance of the astrogeodetic observation}

The main purpose of the ACSYS2 in Turkey is for local geoid determination, though it can also contribute to regional and national geoid models. For instance, the Turkish National Geodesy Commission's on-going project for height modernisation in Turkey. Since 2015, the goal of the project has been to develop a high-accuracy Turkish 
geoid model using terrestrial and airborne gravity data, GNSS/levelling data, etc. (TNUGG 2011; Simav et al. 2015). In order to create such a high-precision geoid model, homogenous data derived from various techniques can be validated by astrogeodetic VDs from the ACSYS2 or QDaedalus system.

The VDs obtained through astrogeodetic instruments are very important for the validation and development of geoid models, especially in coastal and mountainous regions (Hirt and Bürki 2003; Hirt et al. 2010a). In comparison with other techniques-gravimetric and geodetic techniques - the astrogeodetic technique has many advantages, such as its requirements for shorter observations times. Also, as it is possible to reach optimum accuracy with fewer benchmarks (5-10 BMs $/ 1000 \mathrm{~km}^{2}$ ) with astrogeodetic methods when compared to gravimetric geoid determination methods (Gerstbach 1996), we will save time and energy in geoid modelling development studies. In addition to contributing to geoid determinations, the observed VDs from astrogeodetic instruments can be used for the quality assessment of existing and future GGMs. Therefore, the obtained VDs data from ACSYS2 are valuable tools for independently investigating the quality of gravity data sets and gravity field products.

The astrogeodetic VDs can be estimated by geoid height using GNSS/Levelling data (Heiskanen and Moritz 1967; Ceylan 2009; Vittuari et al. 2016), while the geoid height can be calculated by the astrogeodetic VDs data (Halicioglu et al. 2016). When the astrogeodetic observations are completed for the established GNSS/levelling network, the geoid heights or astrogeodetic VDs can be compared for these purposes. Furthermore, the astrogeodetic VDs can be used to calculate the astrogeodetic geoid (Ayhan and Alp 1995) and many other astrogeodetic applications (cf. Section 1). However, it should be noted that astrogeodetic VDs can also be used for other geoscience research. In geophysics, astrogeodetic VDs can be used to identify the density of anomalies below the Earth's surface (Hirt 2001). In tectonic and geodynamic research, astrogeodetic VDs can be used to detect VDs changes before and after earthquakes (presumably M8 earthquake). For example, Bevis et. al (2016) show that the vertical displacements of the geoid and the crust are in opposite directions. In addition to these, Soler et. al (2013) emphasised that astrogeodetic VDs, accompanied by terrestrial gravity, gradiometric observations, and localized seismology, could disclose shallow underground mass anomalies.

\section{Conclusions}

This paper has described the recent progress of the first Turkish DZCS used to obtain astrogeodetic VDs. The new DZCS design resulted from an effort to update and modernise the ACSYS2. The instrument design of the new DZCS, observation procedures, evaluation of the test data and calculations with these data have been described. The preliminary astrogeodetic test observations were conducted with the ACSYS2 at the main observing station at ITU on five nights. Results of the repeated, comparative VDs observations reveal a VD measurement precision of around $0.3^{\prime \prime}$, which indicate the precision of the instrument.

The determination of DZCS accuracy is one of the biggest challenges for DZCS developers. The most reliable method to establish DZCS accuracy is to use another astrogeodetic instrument with known reliable accuracy. We demonstrate here that it can be done by using the QDaedalus system developed at ETH Zurich. The accuracy level of the QDaedalus is 0.15-0.20" (Hauk et al. 2017; Albayrak et al. 2018c and 2019), which is a satisfactory VDs accuracy. The QDaedalus was used at the ITU test station, which is the same test station used for the ACSYS2. The obtained VD results show that the ACSYS2 produces reliable VDs data (see section 5.2).

The ACSYS2's precision was not improved during the modernisation process. However, accuracy can be found through a more reliable method. The installation and levelling of the ACSYS2 are two-times shorter than for the ACSYS. ACSYS2 is also more stable and user-friendly, and the transportation of the system is easier than the first version.

The ACSYS2 was intended to be used in the Istanbul astrogeodetic network (IAN) for astrogeodetic geoid determinations. The IAN was created using $30 \mathrm{BMs}$ from the Istanbul GPS Triangulation Network (IGTN) and the 
Istanbul Levelling Network (ILN) to avoid the need to run new GPS and levelling measurement campaigns (Ayan et al. 2006). Half of the BMs are pillar BMs which can be re-used for future repeated observations. However, the ACSYS2 cannot be installed on pillar BMs. Therefore, users need to establish new BMs close to the pillar that can use by the ACSYS2. New GPS measurements and levelling should be done for these changed BMs. Many of the IAN's BMs are also located very far from infrastructure. For these reasons, the ACSYS2 is not suitable for use in the IAN. The planned network measurements were done instead with the QDaedalus system (Albayrak and Hirt 2018; Özlüdemir 2018; Albayrak et al. 2019). The observed astrogeodetic VDs from the QDaedalus system in Istanbul can then be used to compare the VDs results which will be obtained by the ACSYS2.

\section{Appendix}

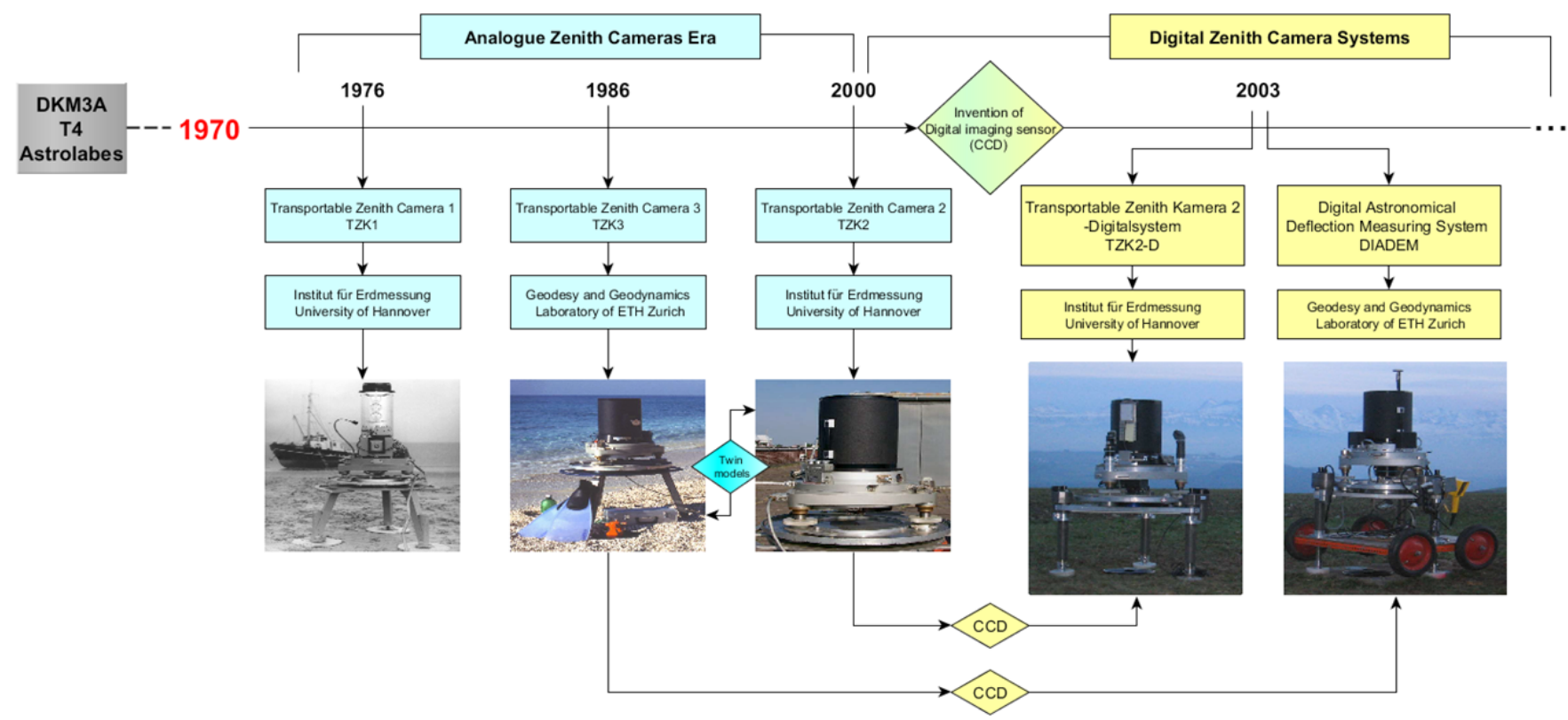

Figure A1: Historical background of the Digital Zenith Camera Systems (Images from Hirt and Bürki 2006).

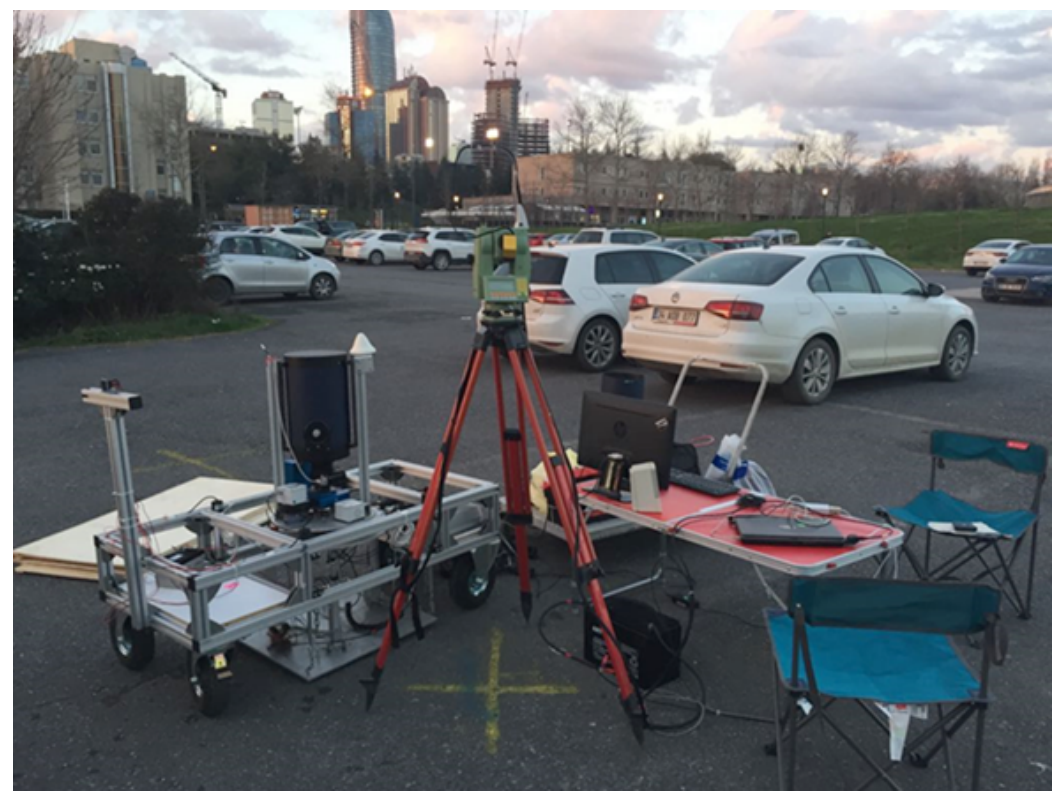

Figure A2: The ACSYS2 and QDaedalus system is deployed at the ITU test station on the same night. 


\section{ACKNOWLEDGEMENT}

The instrument design of the ACSYS2 was developed by Sudo Robotik. This study was supported by the Scientific and Technological Research Council of Turkey (TUBITAK [grant number 115Y237]). MA is grateful to the Fulbright Foundation and to Prof. CK Shum for their support during the writing process of the manuscript. The authors are grateful to Dr. Christian Hirt and Prof. Sebastién Guillaume for their support of the QDaedalus system, and for sharing their TZK2-D, DIADEM and CODIAC DZCSs experience with us. We are grateful to our students who worked as scholarship holders on the TUBITAK projects, MSc. Raşit Uluğ and Seyyid Ali Topal, and to our intern, Alihan Keskin. We also would like to thank Prof. Rahmi Nurhan Çelik, Assoc. Prof. Aydin Ustun and Assist. Prof. Caner Guney for their feedback and constructive comments on the development of the ACSYS2. We would like to thank the Associate Editor who provided insightful and thorough feedback for the manuscript for which we are grateful, and to the reviewers, who provided timely and thoughtful comments. We wish to thank graphic designer Ercan Tuna for ACSYS2's illustration assistance (Figure 6). Figure 11 was drawn using the Generic Mapping Tools (GMT) from Wessel et al. (2013).

\section{AUTHOR'S CONTRIBUTION}

The authors contribute equally

\section{References}

Abele M, Balodis J, Janpaule I, Lasmane I, Rubans A, Zariňš A (2012) Digital zenith camera for vertical deflection determination. Geodesy and Cartography 38(4):123-9. https://doi.org/10.3846/20296991.2012.755324

Albayrak M, Halıcıoğlu K, Başoğlu B, Uluğ R, Özlüdemir MT, Deniz R (2017) Modernizing and upgrading the astrogeodetic camera system for determining vertical deflections. In: AGU Fall Meeting 2017. http://adsabs.harvard. edu/abs/2017AGUFM.G54A..07A

Albayrak M, Hirt C (2018) Determining the astrogeodetic geoid profile of the Munich region using the QDaedalus system. TUBITAK BIDEB 2214-A Final Report, p.63.

Albayrak M, Başoğlu B, Halıcıoğlu K, Özlüdemir MT (2018a) Astrogeodetic test observation by the newly designed astrogeodetic camera system version 2. In: EGU General Assembly 2018. http://adsabs.harvard.edu/ abs/2018EGUGA..20.3980A

Albayrak M, Halıcıoğlu K, Başoğlu B Özlüdemir MT (2018b) Astro-jeodezik zenit kamera sistemi (Astro-geodetic zenith camera system). In: Türkiye Ulusal Jeodezi ve Jeofizik Birliği Bilimsel Kongresi [In Turkish].

Albayrak M, Hirt C, Guillaume S, Hauk M, Halıcıoğlu K (2018c) Testing the QDaedalus measurement system for astrogeodetic observation of the gravity field. In: AGU Fall Meeting 2018. http://adsabs.harvard.edu/ abs/2018AGUFM.G51F0534A

Albayrak M, Hirt C, Guillaume S, Özlüdemir MT, Halıcıŏlu K, Başoğlu B (2019) New astrogeodetic observations of vertical deflections at the Istanbul astrogeodetic network demonstrate issues in global gravity models along coastlines. In: $27^{\text {th }}$ IUGG General Assembly. 
Ayan T, Deniz R, Arslan E, Celik RN, Denli HH, Akyılmaz O, Ozsamlı C, Ozludemir MT, Erol S, Erol B, Acar M, Mercan H, Tekdal E (2006) Istanbul GPS nirengi ağı (IGNA) 2005-2006 yenileme ölçü ve değerlendirmesi (Istanbul GPS triangulation network (IGTN) 2005-2006 re-measurements and data processing). Istanbul Technical University Report 2005 /3123, vol. 1, Istanbul, Turkey, p. 186 [In Turkish].

Ayhan ME, Alp O (1995) Türkiye astro-jeodezik jeodi-1994 (Astrogeodetic geoid in Turkey-1994) In: Türk Haritacılığının 100.yilı TUJJB ve TUFUAB Kongresi (p.307-20).

Başoğlu B, Halıcıoğlu K, Albayrak M, Uluğ R, Özlüdemir MT, Deniz R (2017) An Investigation on the use of different centroiding algorithms and star catalogs in astro-geodetic observations. In EGU General Assembly 2017. http:// adsabs.harvard.edu/abs/2017EGUGA..1915974B

Başoğlu B (2019) Sayısal zenit kamera sisteminin modernizasyonu ve otomasyonu (Modernization and automation of the digital zenit camera system), Master Thesis, Istanbul Technical University, Istanbul, Turkey [In Turkish].

Bevis M, Melini D, Spada G (2016) On computing the geoelastic response to a disk load. Geophysical Journal International 205(3):1804-12. https://doi.org/10.1093/gji/ggw115

Birardi G (1976) The establishment of a net of vertical deflection points in Italy by means of a photo-astronomical procedure. Bollettino di Geodesia e Scienzi Affini 35:113-52.

Bürki B (1989) Integrale Schwerefeldbestimmung in der Ivrea-Zone und deren geophysikalische Interpretation Geodätischgeophysikalische Arbeiten in der Schweiz, Nr. 40, Schweizerische Geodätische Kommission [In German].

Bürki B, Marti U (1991) The Swiss geoid computation: A status report. In Determination of the Geoid, Springer, New York, NY (p.220-29).

Bürki B, Müller A, Kahle HG (2004) DIADEM: The new digital astronomical deflection measuring system for highprecision measurements of deflections of the vertical at ETH Zurich. In: Marti $U$ et al (ed) Electronic proceedings of IAG GGSM2004 meeting in Porto, Portugal. Published also in CHGeoid2003, Report 03-33 A, Bundesamt für Landestopographie (swisstopo), Wabern, Schweiz.

Bürki B, Guillaume S, Sorber P, Oesch HP (2010) DAEDALUS: A versatile usable digital clip-on measuring system for total stations. In 2010 International Conference on Indoor Positioning and Indoor Navigation. IEEE. https://doi. org/10.1109/IPIN.2010.5646270

Ceylan A (2009) Determination of the deflection of vertical components via GPS and levelling measurement: A case study of a GPS test network in Konya, Turkey. Scientific Research and Essays 4(12):1438-44. https://academicjournals. org/journal/SRE/article-full-text-pdf/E6CB7F919837

Charalampous E, Psimoulis P, Guillaume $S$, Spiridonakos $M$, Klis R, Bürki B, Rothacher $M$, Chatzi E, Luchsinger R, Feltrin $G$ (2015) Measuring sub-mm structural displacements using QDaedalus: A digital clip-on measuring system developed for total stations. Applied Geomatics 7(2):91-101. https://doi.org/10.1007/s12518-014-0150-z

Chesi G (1984) Entwicklung einer tragbaren Zenitkammer und ihr Einsatz im 47. Parallel, Deutsche Geodätische Kommission C, München, 287 [In German].

Featherstone WE, Rüeger JM (2000) The importance of using deviations of the vertical in the reduction of terrestrial survey data to a geocentric datum. Trans-Tasman Surv 1(3):46-61. https://doi.org/10.1080/00050326.2000.10440 341. [Erratum in The Australian Surveyor 47(1):7] https://doi.org/10.1080/00050356.2002.10558836

Gerstbach G (1996) How to get a European centimeter geoid ("astro-geological geoid"). Physics and Chemistry of the Earth 21(4):343-6. https://doi.org/10.1016/S0079-1946(97)00059-1

Gessler J (1975) Entwicklung und Erprobung einer transportablen Zenitkamera für astronomisch-geodätische Ortsbestimmungen. Wiss. Arb. Lehrst. für Geod., Phot. und Kart. Techn. Univ. Hannover Nr. 60 [In German].

Guillaume S, Bürki B, Griffet S, Durand HM (2012) QDaedalus: Augmentation of total stations by CCD sensor for automated contactless high-precision metrology. In FIG Working Week. http://www.fig.net/resources/proceedings/ fig_proceedings/fig2012/papers/ts09i/TS09I_guillaume_buerki_et_al_6002.pdf 
Guillaume S (2015) Determination of a precise gravity field for the CLIC feasibility studies. PhD Thesis, Dissertation Nr. 22590, Eidgenössische Technische Hochschule ETH Zurich, Switzerland. https://doi.org/ 10.3929/ethz-a-010549038

Guillaume S, Clerc J, Bürki B (2015) QDaedalus digital clip-on measuring system for total station user manual, Institute of Geodesy and Photogrammetry, Geodesy and Geodynamics Laboratory, ETH Zurich, Switzerland.

Guillaume S, Clerc J, Leyder C, Ray J, Kistler M (2016) Contribution of the image-assisted theodolite system QDaedalus to geodetic static and dynamic deformation monitoring. In 3rd Joint International Symposium on Deformation Monitoring (JISDM). http://www.fig.net/resources/proceedings/2016/2016_03_jisdm_pdf/nonreviewed/JISDM_2016_ submission_66.pdf

Halıcıoğlu K, Deniz R, Özener H (2008) Current geoid studies in Turkey and the need for local high-precision astrogeodetic geoid determination using CCD-zenith cameras. In AGU Fall Meeting 2008. http://adsabs.harvard. edu/abs/2008AGUFM.G51B0613H

Halıcıoğlu K, Deniz R, Özener H (2012) Digital zenith camera system for astro-geodetic applications in Turkey. Journal of Geodesy and Geoinformation 1 (2): 115-20. https://www.hkmo.org.tr/resimler/ekler/37443fe70804150_ek.pdf

Halıcıoğlu K (2015) Sayısal zenit kamera sistemi ile astro-jeodezik çekül sapmalarının belirlenmesi (Determination of Astro-Geodetic deflections of the vertical using digital zenith camera system). PhD Thesis, Istanbul Technical University, Istanbul, Turkey [In Turkish].

Halıcıoğlu K, Deniz R, Özener H (2016) Digital astro-geodetic camera system for the measurement of the deflections of the vertical: Tests and results. International Journal of Digital Earth 9 (9): 914-23. https://doi.org/10.1080/1753 8947.2016.1189612

Halıcıoğlu K, Özlüdemir MT, Deniz R, Özener H, Albayrak M, Uluğ R, Başoğlu B (2017a) The Integration of AstroGeodetic Data Observed with ACSYS to the Local Geoid Models Istanbul-Turkey. In EGU General Assembly 2017. http://adsabs.harvard.edu/abs/2017EGUGA..1913072H

Halıcıoğlu K, Özlüdemir MT, Deniz R, Özener H, Albayrak M, Uluğ R, Başoğlu B (2017b) Istanbul astro-jeodezik test ağında sayısal zenit kamera sistemi gözlemleri (Observations at Istanbul astro-geodetic network using digital zenith camera system). In 16. Türkiye Harita Bilimsel ve Teknik Kurultayı [In Turkish]. https://www.hkmo.org.tr/resimler/ ekler/465fc00cfe6c800_ek.pdf

Halıcıoğlu K, Albayrak M, Basoglu B, Kılıç Y (2018) Investigating the Function of the Star Trails to Improve the Determination of Gravity Field. In AGU Fall Meeting 2018. http://adsabs.harvard.edu/abs/2018AGUFM.G51F0529A

Halıcıoğlu K, Albayrak M, Basoglu B, Kılıç Y (2019) Modelling star trailed images of DZCS to improve the astrogeodetic geoid of Istanbul. In EGU General Assembly 2019. https://meetingorganizer.copernicus.org/EGU2019/ EGU2019-11305.pdf

Hauk M, Hirt C, Ackermann C (2017) Experiences with the QDaedalus system for astrogeodetic determination of deflections of the vertical. Survey Review 49(355): 294-301. https://doi.org/10.1080/00396265.2016.1171960

Heiskanen WA, Moritz H (1967) Physical geodesy. Bulletin Géodésique (1946-1975) 86(1):491-2.

Hirt C (2001) Automatic determination of vertical deflections in real-time by combining GPS and digital Zenith Camera for solving the "GPS-Height-Problem". In 14th International Technical Meeting of The Satellite Division of the Institute of Navigation 2001 (p.2540-51). Inst Navigation.https://espace.curtin.edu.au/bitstream/ handle/20.500.11937/12388/157165_157165.pdf?sequence=2

Hirt C, Bürki B (2003) The digital zenith camera-a new high-precision and economic astrogeodetic observation system for real-time measurement of deflections of the vertical. In 3rd Meeting International Gravity and Geoid Commission of the International Association of Geodesy (p.161-6). Editions Ziti. https://espace.curtin.edu.au/ handle/20.500.11937/15374

Hirt C (2004) Entwicklung und Erprobung eines digitalen Zenitkamerasystems für die hochpräzise Lotabweichungsbestimmung. PhD Thesis, Wissen. Arb. Fach. Vermessungswesen Univ. Hannover Nr. 253 [In German]. http://edok01.tib.uni-hannover.de/edoks/e01dh04/393223965.pdf 
Hirt C, Kahlmann T (2004) Hochpräzise Neigungsmessung mit dem elektronischen Pendelneigungssensor HRTM (Deviation measurement with the electronic HRTM titmeter) Zeitschrift für Vermessungswesen 129:266-76 [In German].

Hirt C, Reese B, Enslin H (2005) On the accuracy of vertical deflection measurements using the high-precision digital zenith camera system TZK2-D. In Gravity, Geoid and Space Missions (p.197-201). Springer, Berlin, Heidelberg. https:// doi.org/10.1007/3-540-26932-0_34

Hirt C (2006) Monitoring and analysis of anomalous refraction using a digital zenith camera system. Astronomy \& Astrophysics 459(1):283-90.https://doi.org/10.1051/0004-6361:20065485

Hirt C, Bürki B (2006) Status of Geodetic Astronomy at the Beginning of the 21st Century. In: Festschrift Univ.- Prof. Dr.- Ing. Prof. h.c. Günter Seeber anlässlich seines 65, Geburtstages und der Verabschiedung in den Ruhestand, (Hirt C., Ed.), Wissenschaftliche Arbeiten der Fachrichtung Geodäsie und Geoinformatik an der Universität Hannover 258: 81-99. http://ddfe.curtin.edu.au/gravitymodels/ERTM2160/pdf/Hirt_Buerki2006_status_geodetic_astronomy.pdf

Hirt C, Flury J (2008) Astronomical-topographic levelling using high-precision astrogeodetic vertical deflections and digital terrain model data. Journal of Geodesy 82(4-5):231-48. https://doi.org/10.1007/s00190-007-0173-x

Hirt C, Seeber G (2008) Accuracy analysis of vertical deflection data observed with the Hannover Digital Zenith Camera System TZK2-D. Journal of Geodesy 82(6):347-56. https://doi.org/10.1007/s00190-007-0184-7

Hirt C (2010) Prediction of vertical deflections from high-degree spherical harmonic synthesis and residual terrain model data. Journal of Geodesy 84(3): 179-90. https://doi.org/10.1007/s00190-009-0354-x

Hirt C, Bürki B, Somieski A, Seeber G (2010a) Modern determination of vertical deflections using digital zenith cameras. Journal of Surveying Engineering 136(1): 1-12. https://ascelibrary.org/doi/pdf/10.1061/\%28ASCE\%29SU.1943-5428.0000009

Hirt C, Guillaume S, Wisbar A, Bürki B, Sternberg H (2010b) Monitoring of the refraction coefficient in the lower atmosphere using a controlled setup of simultaneous reciprocal vertical angle measurements. Journal of Geophysical Research: Atmospheres 115(D21). https://doi.org/10.1029/2010JD014067

Hirt C, Schmitz M, Feldmann-Westendorff U, Wübbena G, Jahn CH, Seeber G (2011) Mutual validation of GNSS height measurements and high-precision geometric-astronomical leveling. GPS Solutions 15(2):149-59. https://doi. org/10.1007/s10291-010-0179-3

Hirt C (2012) Anomalous atmospheric refraction and comments on 'fast and accurate determination of astronomical coordinates...' (Balodimos et al., 2003. Survey Review, 37 (290): 269-75). Survey Review 44(327):285-9. https://doi. org/10.1179/175227012X13455477714906

Hirt C, Claessens S, Fecher T, Kuhn M, Pail R, Rexer M (2013) New ultrahigh-resolution picture of Earth's gravity field. Geophysical research letters 40(16):4279-83. https://doi.org/10.1002/grl.50838

Hirt C, Papp G, Pál A, Benedek J, Szũcs E (2014) Expected accuracy of tilt measurements on a novel hexapod-based digital zenith camera system: a Monte-Carlo simulation study. Measurement Science and Technology 25(8):085004. https://doi.org/10.1088/0957-0233/25/8/085004

Jekeli C (1999) An analysis of vertical deflections derived from high-degree spherical harmonic models. Journal of Geodesy 73(1): 10-22. https://doi.org/10.1007/s001900050213

Kahlmann T, Hirt C, Ingensand H (2004) Hochpräzise neigungsmessung mit dem elektronischen einachspendelsystem hrtm. In 14th International Conference on Engineering Surveying. (p.15-19) [In German]. http://www.geometh-data. ethz.ch/downloads/kahlmann_hrtm_iv2004.pdf

Kaplan GH, Hughes JA, Seidelmann PK, Smith CA, Yallop BD (1989) Mean and apparent place computations in the new IAU system. III-Apparent, topocentric, and astrometric places of planets and stars. The Astronomical Journal 97:1197-210.

Kaplan GH (2005) The IAU resolutions on astronomical reference systems. Time Scales, and Earth Rotation Models. https://arxiv.org/abs/astro-ph/0602086 
Kaplan G, Bartlett J, Monet A, Bangert J, Puatua W (2011) User's guide to NOVAS version F3. 1. USNO, Washington, DC. Kudrys J (2007) Automatic determination of vertical deflection components from GPS and zenithal star observations. Acta Geodynamica et Geomaterialia 4(4):169-172. https://www.irsm.cas.cz/materialy/acta_content/2007_04/18_ Kudrys.pdf

Lafreniere D, Marois C, Doyon R, Nadeau D, Artigau É (2007) A new algorithm for point-spread function subtraction in high-contrast imaging: a demonstration with angular differential imaging. The Astrophysical Journal 660(1):770780. https://iopscience.iop.org/article/10.1086/513180

Lauer TR (1999) The photometry of undersampled point-spread functions. Astronomical Society of the Pacific 111(765):1434. https://iopscience.iop.org/article/10.1086/316460/pdf

Müller II (1969) Spherical and practical astronomy as applied to geodesy. New York, Frederick Ungar Publishing.

Müller A, Bürki B, Kahle HG, Hirt C, Marti U (2005) First results from new high-precision measurements of deflections of the vertical in Switzerland. In Gravity, geoid and space missions 2005 (p.143-48). Springer, Berlin, Heidelberg. https://doi.org/10.1007/3-540-26932-0_25

Özlüdemir MT (2018) Astro-jeodezik ve GNSS/Nivelman verilerinin entegrasyonu ile yersel geoit modellemesi (Local geoid modelling using integrated astro-geodetic and GNSS/Levelling data). TUBITAK 1001 Project Final Report (No: 115Y237) [In Turkish].

Pavlis NK, Holmes SA, Kenyon SC, Factor JK (2012) The development and evaluation of the Earth Gravitational Model 2008 (EGM2008). Journal of geophysical research: solid earth 117(B4). https://doi.org/10.1029/2011JB008916

Pavlis NK, Holmes SA, Kenyon SC, Factor JK (2013) Correction to "The development and evaluation of the Earth Gravitational Model 2008 (EGM2008)" Journal of Geophysical Research: Solid Earth 118(5):26-33. https://doi. org/10.1002/jgrb.50167

Pick M, Picha J, Vyskočil V (1973) Theory of earth's gravity field. Amsterdam, London, New York: Elsevier Scientific Publishing Company.

Pinpoint Astrometric Engine (2019) Pinpoint Astrometric Engine home page. http://pinpoint.dc3.com/

Schack P, Hirt C, Hauk M, Featherstone WE, Lyon TJ, Guillaume S (2018) A high-precision digital astrogeodetic traverse in an area of steep geoid gradients close to the coast of Perth, Western Australia. Journal of Geodesy 92(10): 114353. https://doi.org/10.1007/s00190-017-1107-x

Schödlbauer A (2000) Geodätische Astronomie - Aussichten an der Schwelle zum 21. Jahrhundert.25 Jahre Institut für Geodäsie, Schriftenreihe Studiengang Geodäsie und Geoinformation der Universität der Bundeswehr München, Heft 60-1: 27-56 [In German].

Simav M, Yıldız H, Cingöz A, Sezen E, Demirsoy NS, Akpınar I, Okay H, Gürer A, Akçakaya M, Yılmaz S, Akça M, Çakmak R, Karaböce B, Sadıkoğlu E, Doğan U (2011) Türkiye Yükseklik Sisteminin Modernizasyonu ve Gravite Altyapısının İyileştirilmesi Projesi (The modernization of the height system and gravity infrastructure recovery project in Turkey), 15. Türkiye Harita Bilimsel ve Teknik Kurultayı [In Turkish]. https://www.hkmo.org.tr/resimler/ ekler/ed65671df6cd356_ek.pdf

Smart WM (1977) Textbook on spherical astronomy. Cambridge University Press.

Smith DA, Holmes SA, Li X, Guillaume S, Wang YM, Bürki B, Roman DR, Damiani TM (2013) Confirming regional $1 \mathrm{~cm}$ differential geoid accuracy from airborne gravimetry: the geoid slope validation survey of 2011. Journal of Geodesy 87(10-12):885-907. https://doi.org/10.1007/s00190-013-0653-0

Soler T, Han JY, Weston ND (2013) On deflection of the vertical components and their transformations. Journal of Surveying Engineering 140(2):04014005(1-15). https://doi.org/10.1061/(ASCE)SU.1943-5428.0000126

Tian L, Guo J, Han Y, Lu X, Liu W, Wang Z, Wang B, Yin Z, Wang H (2014) Digital zenith telescope prototype of China. Chinese Science Bulletin 59(17):1978-83. https://doi.org/10.1007/s11434-014-0256-z 
TNUGG (2011)Turkish National Union of Geodesyand Geophysics (TNUGG) national report of geodesy commission of Turkey for 2007-2011. https://iag.dgfi.tum.de/fileadmin/IAG-docs/NationalReports2011/Final_TUJK_Report_2007_2011.pdf Torge W, Müller J (2012) Geodesy. 4th edition. De Gruyter, Berlin.

Tóth G, Völgyesi L (2017) Data processing of QDaedalus measurements. Geosciences and Engineering 5(8):147-64. Tóth G, Völgyesi L (2018) Experiences of QDaedalus measuruments. Geosciences and Engineering 6(9):75-86.

Uluğ R, Halıcıoğlu K, Özlüdemir MT, Albayrak M, Başoğlu (2017) Calibration and testing of digital zenith camera system components. In EGU General Assembly 2017. http://adsabs.harvard.edu/abs/2017EGUGA..1916242U

Uluğ R (2017) Sayısal zenit kamera sistemi bileşenlerinin test ve kalibrasyon ölçmeleri (Calibration and testing of digital zenith camera system components). Master Thesis, Istanbul Technical University, Istanbul, Turkey [In Turkish].

Vittuari L, Tini MA, Sarti P, Serantoni E, Borghi A, Negusini M, Guillaume S (2016) A comparative study of the applied methods for estimating deflection of the vertical in terrestrial geodetic measurements. Sensors 16(4):565. https:// doi.org/10.3390/s16040565

Voigt C (2013) Astrogeodätische lotabweichungen zur Validierung von schwerefeldmodellen. Deutsche Geodätische Kommission C 702, München [In German].

Volařík T, Machotka R, Kuruc M, Puchrik L, Jurčík J (2013) Determination of quasigeoid in local network using modern astrogeodetic technologies. Acta Geodynamica et Geomaterialia 10(172):437-42.

Wang B, Tian L, Wang Z, Yin Z, Liu W, Qiao Q, Wang H, Han Y (2014) Image and data processing of digital zenith telescope (DZT-1) of China. Chinese Science Bulletin 59(17):1984-91. https://doi.org/10.1007/s11434-014-0277-7

Wang YM, Becker C, Mader G, Martin D, Li X, Jiang T, Breidenbach S, Geoghegan C, Winester D, Guillaume S, Bürki B (2017) The Geoid slope validation survey 2014 and GRAV-D airborne gravity enhanced geoid comparison results in lowa. Journal of Geodesy 91(10):1261-76. https://doi.org/10.1007/s00190-017-1022-1

WCSTools (2019) WCSTools home page http://tdc-www.harvard.edu/wcstools/

Wessel P, Smith WHF, Scharroo R, Luis JF, Wobbe F (2013) Generic mapping tools: improved version released. Eos, Transactions American Geophysical Union 94(45): 409-10. 94(45): 409-410. https://doi.org/10.1002/2013EO450001

Westrum DV, Ahlgren K, Guillaume S, Hirt C, Martin D, Roman D, Smith D (2019) Field Observation Results from the 2017 Geoid Slope Validation Survey in Colorado, USA. In $27^{\text {th }}$ IUGG General Assembly.

Wissel H (1982) Zur Leistungsfähigkeit von transportablen zenitkameras bei der lotabweichungsbestimmung. Wissen. Arb. Fach. Ver- messungswesen Univ. Hannover Nr. 107 [In German].

Zacharias N, Finch CT, Girard TM, Henden A, Bartlett JL, Monet DG, Zacharias MI (2013) The fourth US naval observatory CCD astrograph catalogue (UCAC4). The Astronomical Journal 145(2):44. https://iopscience.iop.org/ article/10.1088/0004-6256/145/2/44

Zarinšs A, Rubans A, Silabriedis G (2016) Digital zenith camera of the University of Latvia. Geodesy and Cartography 42(4):129-35. http://dx.doi.org/10.3846/20296991.2016.1268434

Zarinš A, Rubans A, Silabriedis G (2018) Performance analysis of Latvian zenith camera. Geodesy and Cartography 44(1):1-5. https://doi.org/10.3846/gac.2018.876 